\title{
Anion Removal Potential of Complex Metal Oxides Estimated from Their Atomic Scale Structural Properties
}

\author{
N. Chubar ${ }^{a, *}$, V. Gerda ${ }^{a}$, M. Mičušík ${ }^{b}$, M. Omastova $^{b}$, K. Heister $^{c}, \mathrm{P}$ Man $^{d}$, \\ G. YABLOKOVA ${ }^{e}$, D. BANERJEE ${ }^{f}$ AND J. FRAISSARD ${ }^{g}$ \\ ${ }^{a}$ Faculty of Chemistry, Taras Shevchenko National University of Kyiv, 01601, Kyiv, Ukraine \\ ${ }^{b}$ Polymer Institute, Slovak Academy of Sciences, 84541, Bratislava, Slovak Republic \\ ${ }^{c}$ GeoLab, Faculty of Geosciences, Utrecht University, 3584 CB Utrecht, The Netherlands \\ ${ }^{d}$ Institut des Matériaux de Paris Centre, Université P. et M. Curie, 75005 Paris, France \\ ${ }^{e}$ Department of Materials Engineering, KU Leuven, 3001 Leuven, Belgium \\ ${ }^{f}$ Dutch-Belgian Beamline (DUBBLE), ESRF - The European Synchrotron CS 40220, Grenoble, France \\ ${ }^{g}$ Université P. et M. Curie, ESPCI-LPEM, 75005 Paris, France
}

\begin{abstract}
The main common idea of two conference papers delivered at OMEE-2017 was to demonstrate an importance of the speciation level knowledge in modern adsorption materials science. In order to prove this, two groups of adsorptive materials were used: three samples of $\mathrm{Mg}-\mathrm{Al}-\mathrm{CO}_{3}$ layered double hydroxides produced by different synthesis methods and ten samples of $\mathrm{Fe}-\mathrm{Ce}$ oxide-based composites with various ratios of $\mathrm{Fe}$-to-Ce. In both cases of studies, it was not possible to find direct correlation between adsorptive performances of the materials and their structural properties obtained by conventional characterisation techniques. However, anion adsorptive removals of each group of inorganic composites correlated with their structural properties studied on the level of speciation. It was shown that strong anion removal potential of $\mathrm{Mg}-\mathrm{Al}-\mathrm{CO}_{3}$ layered double hydroxides was associated with richness in speciation of chemical elements $(\mathrm{Mg}, \mathrm{Al})$ and interlayer anions $\left(\mathrm{CO}_{3}^{2-}\right)$ as well as with generous hydration. Adsorptive performances of inorganic anion exchangers based on $\mathrm{Fe}-\mathrm{Ce}$ hydrous oxides were explained by simulation extended X-ray absorption fine structures simulation. The best anion removers were found to be those $\mathrm{Fe} / \mathrm{Ce}$ oxide-based composites whose Fe outer shells were formed from backscattering oscillations from both $\mathrm{O}$ and $\mathrm{Fe}$ atoms.
\end{abstract}

DOI: 10.12693/APhysPolA.133.1091

PACS/topics: 81.05.Je, 81.05.Rm, 68.43.-h, 82.80.-d

\section{Introduction}

Inorganic anion exchangers are relatively recent group of adsorptive materials. They came into water market in the beginning of 21st century to meet increasingly stronger maximum allowable concentrations (MAC) to toxic anions, first of all, to arsenic [1]. The newly established MAC $(10 \mu \mathrm{g} / \mathrm{l})$ required highly selective materials and technologies. The "right" chemical nature for the adsorbents, which shall be able to reduce As concentrations from 50 (old standard) to $10 \mu \mathrm{g} / \mathrm{l}$, are metal oxides [2]. These materials remove toxic anions via the main primary anion exchange mechanism, which is an exchange of surface $\mathrm{OH}^{-}$groups for aqueous anions (such as $\mathrm{H}_{2} \mathrm{AsO}_{4}^{-}$). Consequently, an abundance of surface $\mathrm{OH}^{-}$ is one of the factors that predetermine an efficiency of anion removal processes by inorganic anion exchangers. The other factors were meant to be established. Numerous publications demonstrated that materials of the same chemical formula can exhibit dramatically different performances in adsorption and catalysis. Notably, the standard characterisation methods did not explain

*corresponding author; e-mail: natachubar@yahoo.com the removal efficiencies of inorganic adsorbents. Nor the particle size approach, used in nanotechnology, was able to explain the processes at the interfaces between inorganic anion exchangers and aqueous phases. Based on the mentioned above, the explanations for the material adsorptive performances shall be looked for at beyond the nanoscale.

Adsorption phenomenon depends on excess energy at the interface, which is a function of material disorder. As a rule, single-phase crystalline materials have low removal capacities to aqueous ions compared with amorphous or reduced crystallinity adsorbents. In the same time, the main method used to characterise such materials is X-ray diffraction patterns (XRD) that does not allow identification of amorphous phases. This creates the situation when a considerable part of composite inorganic adsorbents might be left uncharacterised. The main methods that allow the characterization of such complex inorganic material is the extended X-ray absorption fine structure (EXAFS) and X-ray absorption near edge structure (XANES). Moreover, our recent works [3, 4] demonstrated that EXAFS/XANES could be more useful than previously thought. Most researchers in adsorption science focus their EXAFS studies on adsorbate to determine adsorption mechanism of sorbed ions, however, detailed characterisation of inorganic adsorbent structure 
by EXAFS can provide very important information on the material which can be related to its (an)ion exchange potential. Such approach has never been explored up to now $[3,4]$.

The overall goal of this work was using two cases of studies on complex metal oxides (and considerable amount of research data) to demonstrate that nowadays the progress in adsorption science and adsorption technology depends on the atomic scale knowledge of adsorptive material structures.

The main tasks within this goal were:

- Using three $\mathrm{Mg}-\mathrm{Al}-\mathrm{CO}_{3}$ layered double hydroxides (LDHs) to demonstrate an importance of richness in speciation (of chemical elements and phases) in the material structures for their anion removal performances; and to relate each speciation study to corresponding material characterisation tools.

- To show an applicability of EXAFS/XANES techniques in estimation of anion exchange potential of ten $\mathrm{Fe}-\mathrm{Ce}$ hydrous oxides from local structures around $\mathrm{Fe}$ and Ce simulated by using Fe $K$-edge and Ce $L_{3}$-edge EXAFS spectra.

\section{Experimental}

\subsection{Materials}

Two groups of the adsorptive materials based on complex metal oxides were used in this study. One of them was based on $\mathrm{Mg}-\mathrm{Al}-\mathrm{CO}_{3} \mathrm{LDH}$ synthesized by three different methods: alkoxide sol-gel synthesis (commercial material by Sasol denoted here as ASG), hydrothermal precipitation in the presence of urea (research sample denoted here as HTP) and fine inorganic synthesis with a step of alkoxide-free sol-gel transformations (research sample denoted here as AFSG). See detailed description in $[5,6]$. The other group were ten inorganic composites based on $\mathrm{Fe}-\mathrm{Ce}$ hydrous oxides prepared under the urea $\left(\mathrm{CO}\left(\mathrm{NH}_{2}\right)_{2}\right)$-based hydrothermal conditions [3, 4], just like the LDHs sample denoted HTP. The materials chemistry of hydrothermal synthesis was underpinned by the release of $\mathrm{OH}^{-}$and $\mathrm{CO}_{2}$ into the aqueous medium which resulted in co-precipitation of inorganic composites based on $\mathrm{Fe}$ and $\mathrm{Ce}$ hydrous oxides. It was expected that the presence of $\mathrm{CO}_{2}$ might result in formation of some carbonate containing compounds which might ease the phase transformations at thermal treatments. Five dosage ratios of $\mathrm{Fe}(\mathrm{II}) / \mathrm{Ce}(\mathrm{III})$ were used in this synthesis: $1 \mathrm{Fe}-0 \mathrm{Ce}, 2 \mathrm{Fe}-1 \mathrm{Ce}, 1 \mathrm{Fe}-1 \mathrm{Ce}, 1 \mathrm{Fe}-2 \mathrm{Ce}$, and $0 \mathrm{Fe}-1 \mathrm{Ce}$. Autoclave precipitates were dried at ambient temperature first and then treated at 80 and $300^{\circ} \mathrm{C}$, which resulted in ten samples in total $[3,4]$ denoted here as Fe, $\mathrm{Fe} 2 \mathrm{Ce} 1, \mathrm{Fe} 1 \mathrm{Ce} 1, \mathrm{Fe} 1 \mathrm{Ce} 2$, and $\mathrm{Ce}$ with extensions -80 or -300 , respectively.

\subsection{Methods}

Detailed information on all methods used to characterise these two groups of the materials (three $\mathrm{Mg}-$ $\mathrm{Al}$ LDHs and ten Fe-Ce-oxide-based composites) can be found in [3-6]. Here are brief descriptions of some techniques, which allow direct access to the speciation information. The ${ }^{27} \mathrm{Al}$ solid-state MAS NMR (nuclear magnetic resonance) spectra were performed on a Bruker Avance-500 multinuclear spectrometer operating at a ${ }^{27} \mathrm{Al}$ resonance frequency of $130.3 \mathrm{MHz}$. Its chemical shifts were referenced to an external standard $\left[\mathrm{Al}\left(\mathrm{H}_{2} \mathrm{O}\right)_{6}\right]^{3+}$ in ppm. MAS spectra were collected using a $4 \mathrm{~mm}$ diameter zirconia rotor spinning at $12 \mathrm{kHz}$ and 320 scans. A single $\mathrm{PI} / 8$ radiofrequency pulse-flip angle was applied with repetition duration of $1 \mathrm{~s}$. Xray photoelectron (XPS) signals were recorded using a Thermo Scientific K-Alpha XPS system (Thermo Fisher Scientific, UK) that was equipped with a micro-focused, monochromatic Al $K_{\alpha}$ X-ray source $(1486.6 \mathrm{eV})$. An Xray beam of $400 \mu \mathrm{m}$ size was applied at $6 \mathrm{~mA}$ and $12 \mathrm{kV}$. The spectra were collected in the constant analyser energy mode with a pass energy of $200 \mathrm{eV}$ for the survey. Narrow regions were used with a pass energy of $50 \mathrm{eV}$. The Fourier-transform infrared (FTIR) spectra were written within the range of 400 to $4000 \mathrm{~cm}^{-1}$ using a Nicolet 6700 Fourier transform infrared spectrometer (conventional $\mathrm{KBr}$ pellet was applied in transmission mode recording). Fe $K$-edge $(7112 \mathrm{eV})$ and $\mathrm{Ce}$ $L_{3}$-edge $(5723 \mathrm{eV})$ EXAFS/XANES spectra were written at the Dutch-Belgian (DUBBLE) beamline (BM26A) of European Synchrotron Radiation Facilities (ESRF), Grenoble, France. On the station DUBBLE, a Si(111) double-crystal monochromator was supplied. The spectra were collected in the transmission detection mode (at room temperature). Details on the experimental setup of DUBBLE beamline are described in [7]. The Athena, Artemis, and Atoms software packages were used to process and simulate EXAFS data [8]. The linear combination fitting (LCF) option of Athena was applied to estimate compositions of these composites and the ratios of various compounds in their structure. A number of the experimental references were used for LCF. To simulate the local structures around Fe and Ce atoms, Feff.inp files were generated using the crystallographic information of several relevant reference compounds [3, 4] shown in the literature and found in the database of the software developers, available online.

\section{Results and discussion}

\subsection{Layered double hydroxides: synthetic method versus anion removal properties}

Layered double hydroxides (LDHs) are rare in nature white hydrous minerals with a rhombohedral crystalline system of general formula

$$
\left[\mathrm{M}_{1-x}^{2+} \mathrm{M}_{x}^{3+} \times(\mathrm{OH})_{2}\right]^{q+}\left(\mathrm{A}^{\mathrm{n}-}\right)_{\frac{q}{\mathrm{n}}} \cdot \mathrm{mH}_{2} \mathrm{O},
$$

where $\mathrm{M}^{2+}$ usually represents metallic divalent cations such as $\mathrm{Mg}, \mathrm{Ca}, \mathrm{Zn}, \mathrm{Mn}(\mathrm{II}), \mathrm{Ni}(\mathrm{II}), \mathrm{Fe}(\mathrm{II}), \mathrm{Co}(\mathrm{II})$ etc., $\mathrm{M}^{3+}$ represents typically trivalent cations such as $\mathrm{Al}$ or $\mathrm{Fe}(\mathrm{III}), \mathrm{A}^{n-}$ is the interlayer anion of charge $n$. In mineralogy such materials are often associated with serpentine 
and calcite [9]. Nowadays, greater variety of the metal oxidation states in these layered compounds was preserved by researchers.

These anionic clays discovered in 1842 [10] are also known as hydrotalcites (HT). LDHs are considered as the next generation anion exchangers [11] due to their layered structure which allows hosting an additional amount of aqueous anions in their interlayer space. Layered structure and the interlayer space make the LDHs superior to any other metal oxide of bulk structure. Bulk structure oxide-based adsorbents involve only surface anion exchange groups, often $\mathrm{OH}^{-}$, in the removal of aqueous anions. LDHs can exhibit two strong anion removal possibilities: exchange of surface $\mathrm{OH}^{-}$and replacement of the interlayer anions for aqueous anions. However, the literature review by the authors [11] showed that the removal performances of various LDHs differed considerably; also that most HTs are unable for direct ion exchange of their interlayer anions with aqueous anions. To find explanation for the above differences in HTs adsorptive properties, deeper insight on the structures of three LDHs (ASG, HTP, and AFSG) produced by different synthetic methods was gained; the structural differences of these three materials were further associated with their adsorptive properties. Figure 1 shows that adsorptive capacities of three $\mathrm{Mg}-\mathrm{Al}-\mathrm{CO}_{3} \mathrm{LDHs}$ to several toxic anions differed considerably.

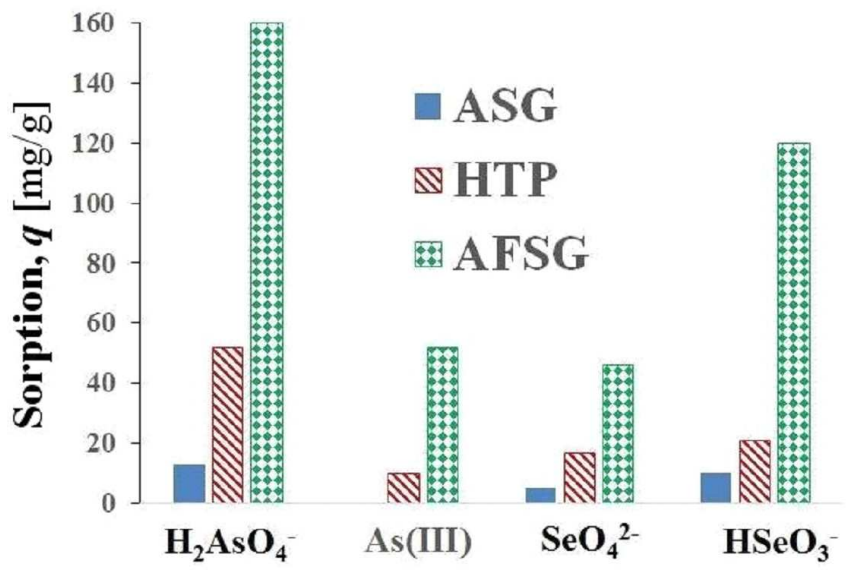

Fig. 1. Adsorptive performances of three $\mathrm{Mg}-\mathrm{Al}-\mathrm{CO}_{3}$ LDHs prepared by ASG, HTP, and AFSG to several aqueous anions. Experimental conditions: adsorbent dose $=2 \mathrm{~g} / \mathrm{l}, \mathrm{pH}=7$, background electrolyte $0.01 \mathrm{NaCl}$. Modified from [5].

FTIR spectroscopy demonstrated that two LDHs (ASG and HTP) did not involve their interlayer $\mathrm{CO}_{3}^{2-}$ in the removal of aqueous anions [5], which means that these two layered complex oxides acted as bulk structure adsorbents. They involved only surface $\mathrm{OH}^{-}$in the removal mechanism. In contrast to ASG and HTP, the third $\mathrm{Mg}-\mathrm{Al}-\mathrm{CO}_{3}$ LDHs (AFSG) indeed involved its interlayer carbonate in adsorption of the same aqueous anions.
Standard surface characterisation methods (potentiometric titration and zeta potential measurements) did not show considerable differences between ASG, HTP, and AFSG [5]. Based on the surface chemistry data, one would expect a nearly equal anion removal capacities of these three LDHs; however, adsorptive performances of the three LDHs differed dramatically from each other, see Fig. 1.

These HTs differed however in porosity and crystallinity but the differences in their porous structures were not directly proportional to their adsorptive properties [5]. In order to find an explanation for the adsorptive performances of ASG, HTP, and AFSG, they were characterised on the speciation level by going beyond the nanoscale.

\subsubsection{Speciation of aluminium $(\mathrm{Al})$ by $N M R$ and XPS}

${ }^{27} \mathrm{Al} \mathrm{NMR}$ spectra are shown in [5]. It was determined that the main Al species in ASG, HTP and AFSG had octahedral geometry. For commercial $\mathrm{Mg}-\mathrm{Al} \mathrm{LDHs}$ (ASG), it was the only $\mathrm{Al}$ species in its structure. HTP had small concentration of tetrahedral geometry $\mathrm{AlO}_{4}$ in addition to the main species, $\mathrm{AlO}_{6}$. AFSG contained more $\mathrm{Al}$ species than the other two samples. Except for major species, $\mathrm{AlO}_{6}$, it also had some $\mathrm{AlO}_{4}$ and $\mathrm{AlO}_{5}$.

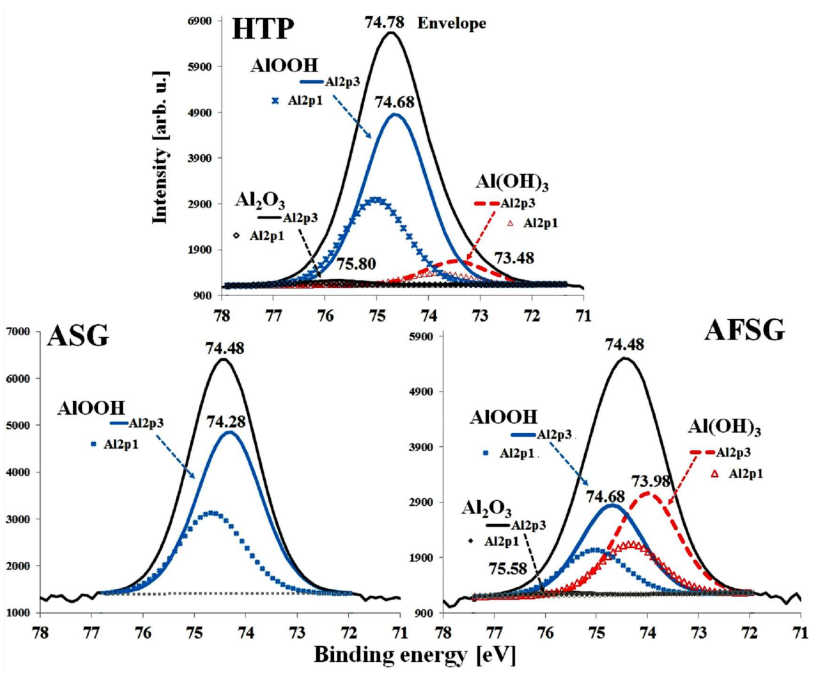

Fig. 2. Al $2 p$ XPS spectra for ASG, HTP, and AFSG.

Speciation of $\mathrm{Al}$ on the surface was estimated from $\mathrm{Al} 2 p$ XPS spectra (Fig. 2). The data on $\mathrm{Al}$ speciation by NMR and XPS correlated well with each other. As shown in Fig. 2, commercial LDHs (ASG) had strictly one species of $\mathrm{Al}$ on its surface. In HTP, Al was dominated by one species as well, however small portion of different species was also measured. AFSG had richer speciation of surface Al than HTP and ASG. Skilled decomposition of the main peak resulted in defining three major $\mathrm{Al}$ species $\left(\mathrm{AlOOH}, \mathrm{Al}_{2} \mathrm{O}_{3}\right.$, and $\left.\mathrm{Al}(\mathrm{OH})_{3}\right)$; and this speciation information allowed associating the relative content of $\mathrm{Al}(\mathrm{OH})_{3}$ in each material with its adsorptive removal. Commercial $\mathrm{Mg}-\mathrm{Al}-\mathrm{CO}_{3} \mathrm{LDH}(\mathrm{ASG})$ that 
did not contain $\mathrm{Al}(\mathrm{OH})_{3}$ had the weakest anion removal properties, Fig. 1. Minor presence of $\mathrm{Al}(\mathrm{OH})_{3}$ among $\mathrm{Al}$ species in HTP correlated well with its average adsorptive capabilities to aqueous anions. Finally, outstanding anion adsorptive properties of AFSG were in agreement with the highest portion of $\mathrm{Al}(\mathrm{OH})_{3}$ among $\mathrm{Al}$ phases in its structure. Most probably, $\mathrm{Al}(\mathrm{OH})_{3}$ played the most important role in adsorption of the investigated anions as compared with the other two phases, $\mathrm{AlOOH}$, and $\mathrm{Al}_{2} \mathrm{O}_{3}$.

\subsubsection{Speciation of magnesium $(\mathrm{Mg})$ studied by XPS}

$\mathrm{Mg} 1 s$ XPS spectra can be found in [11]. Two sol-gel generated samples (ASG and AFSG) had richer speciation of $\mathrm{Mg}$ on the surface compared to hydrothermally precipitated LDHs (HTP).

\subsubsection{Speciation of the interlayer carbonate $\left(\mathrm{CO}_{3}^{2-}\right)$ in- vestigated by FTIR}

Since the interlayer space makes LDHs superior to bulk structure metal oxides, speciation of the interlayer carbonate and the factors, which predetermine its exchangeability potential with aqueous anions, play a leading role in applicability of these materials in water purification. Monodentate coordination of the interlayer anions is preferred to bidentate due to its weaker binding to the layers, which potentially shall ease its exchangeability with aqueous anions. It was found that three HTs had different speciation of the interlayer carbonate. ASG prepared by alkoxide sol-gel method at industrial scales had only one species of the interlayer $\mathrm{CO}_{3}^{2-}$. Hydrothermally precipitated LDHs had few species of the interlayer carbonate most of which had bidentate coordination. The third $\mathrm{Mg}-\mathrm{Al}-\mathrm{CO}_{3} \mathrm{LDHs}$ produced by inorganic alkoxidefree sol-gel method had several carbonate species all of which had monodentate coordination.

\subsubsection{The role of hydration of $\mathrm{Mg}-\mathrm{Al} L D H s$}

Hydration is of double importance for LDHs, which are expected to act as anion exchangers. First, surface reactivity depends on concentration of surface $\mathrm{OH}^{-}$groups, which is a function of hydration. Secondly, exchangeability of the interlayer carbonate (as a second anion removal mechanism) also depends on hydration of both the surface and the interlayer. In overall, adsorptive performances of LDHs depend on their hydration with physisorbed water and interlayer water both of which shall be abundant. However, critical view on HTs properties using the literature data demonstrated that nearly all LDHs are poorly hydrated materials [11]. Hydration regularities of the three investigated $\mathrm{Mg}-\mathrm{Al} \mathrm{LDHs}$ are shown in Table I. It was found that ASG was a poorly hydrated material. Hydration of HTP was similar to many other LDHs produced by hydrothermal precipitation [11]. Notably, AFSG had the most generous hydration compared to all other LDHs known from the literature [11].

\subsubsection{Richness in speciation versus adsorptive removal}

Speciation level studies of the structure of three LDHs allowed explaining such a considerable differences in their adsorptive performances to aqueous anions, see Fig. 1 and [5]. The worst adsorptive properties were shown by

\section{TABLE I}

Hydration regularities in the three LDHs estimated from thermogravimetrical analysis (TGA): contents of physisorbed water $\left(105^{\circ} \mathrm{C}\right)$ and interlayer water $(105-$ $\left.220^{\circ} \mathrm{C}\right)$. Modified from [11].

\begin{tabular}{c|c|c|c}
\hline \hline $\begin{array}{c}\text { Synthetic } \\
\text { approach }\end{array}$ & $\begin{array}{c}\mathrm{Mg}-\mathrm{Al} \\
\mathrm{LDHs}\end{array}$ & $\begin{array}{c}{[\%]} \\
105^{\circ} \mathrm{C}\end{array}$ & $\begin{array}{c}{[\%]} \\
105-220^{\circ} \mathrm{C}\end{array}$ \\
\hline $\begin{array}{c}\text { alkoxide } \\
\text { sol-gel }\end{array}$ & ASG & $\sim 1$ & $\sim 13$ \\
\hline $\begin{array}{c}\text { urea-based } \\
\text { hydrothermal }\end{array}$ & $\mathrm{HTP}$ & $\sim 6$ & $\sim 11$ \\
\hline $\begin{array}{c}\text { alkoxide-free } \\
\text { sol-gel }\end{array}$ & AFSG & $\sim 18$ & $\sim 23$
\end{tabular}

the commercial HT (ASG) which had poor speciation of the chemical elements and interlayer carbonate, as well as poor hydration. An average adsorptive performance of the hydrothermally precipitated material (HTP) was in accordance with an average speciation of the chemical elements and phases in its structure. Finally, outstanding adsorptive properties of AFSG produced by fine inorganic alkoxide-free sol-gel synthesis were due to richness in speciation of $\mathrm{Al}, \mathrm{Mg}$ and the interlayer carbonate as well as generous hydration. AFSG is the only LDHs till now that exchanges its interlayer carbonate directly with the aqueous anions without even extending its interlayer space. See more in [11].

\subsection{Estimation of anion exchange properties of $\mathrm{Fe}-\mathrm{Ce}$ oxide-based composites from their atomic scale structures studied by using EXAFS/XANES}

3.2.1. An importance of EXAFS/XANES in characterisation of inorganic composites

As mentioned above, characterisation of inorganic adsorbents based on complex metal oxides requires application of both XRD patterns and EXAFS spectroscopy. EXAFS/XANES characterises the entire material even if it might be time-consuming to simulate an extended local structures around atoms, especially, their outer shells. One of the advantageous of EXAFS/XANES is the XANES-based LCF option, which allows defining the ratios between the most probable compounds in the structure of the experimental samples using the spectra of the references collected on the same beamline. Success in LCF fitting depends on the correctly chosen reference materials. Choice of the references shall be based on the structural/chemical information on the experimental samples preliminary obtained by the relevant conventional methods. General advice for such work is to collect 1-2 additional EXAFS spectra from reference materials rather than to miss one.

\subsubsection{Phase composition in the structure of ten compos-} ite adsorbents based on $\mathrm{Fe}-\mathrm{Ce}$ oxides

$\mathrm{Fe}-\mathrm{Ce}$ oxide-based materials were composed by the known crystalline phases, amorphous compounds and some unknown crystalline phases, which required combined application of both XRD and XANES/EXAFS 
supported by FTIR $[3,4]$. XRD confirmed the presence of the known crystalline phases in both Fe and Ce components. XANES-based LCF fitting using a number of the experimental references allowed estimation of general chemical formulas of the main compounds (without distinguishing crystalline and amorphous phases) and the ratios between them $[3,4]$.

3.2.3. Anion removal properties of ten $\mathrm{Fe}-\mathrm{Ce}$ oxide-based composites versus their porosity

There was no correlation between the porous properties of $\mathrm{Fe}-\mathrm{Ce}$ hydrous oxides and their adsorptive removal of four aqueous anions (arsenate, phosphate, fluoride, and bromate) $[3,4]$. Moreover, some samples with the lower specific surface area $\left(S_{B E T}\right)$ had higher adsorptive performances than the materials with higher $S_{B E T}$. Figure 3 reflects this tendency using some data modified from $[3,4]$.
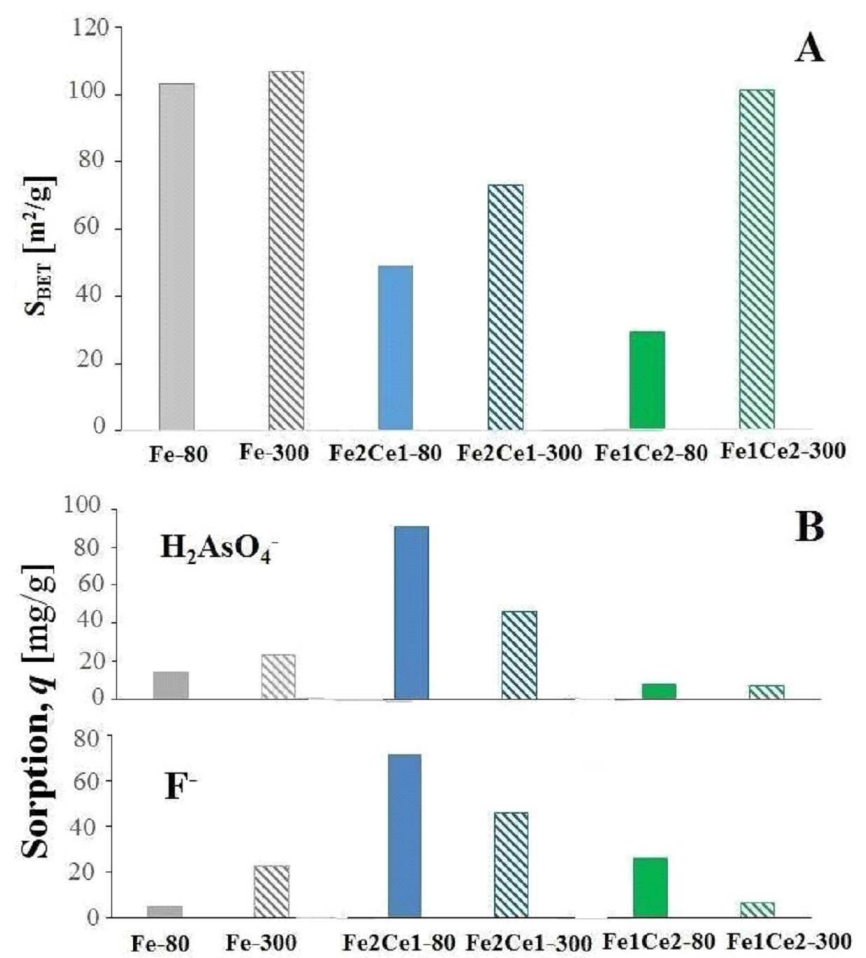

Fig. 3. Specific surface area of Fe-Ce oxide-based composites (A) and their adsorptive removal of arsenate and fluoride studied at the adsorbent dose of $2 \mathrm{~g} / \mathrm{l}$ and the initial anion concentration of $\approx 200 \mathrm{mg} / \mathrm{l}(\mathrm{B})$. Modified from $[3,4]$.

\subsubsection{Adsorptive removal of $\mathrm{Fe}-\mathrm{Ce}$ oxide-based samples versus an extended fine structure around Fe simulated by EXAFS}

Two articles accompanied by supporting materials provide detailed information on the results of EXAFS simulation using both Fe $K$-edge and Ce $L_{3}$-edge EXAFS data for ten samples $[3,4]$. Figure 4 shows radial structure around Fe resulting from the Fourier transforms of
Fe $K$-edge EXAFS oscillations for six $\mathrm{Fe}-\mathrm{Ce}$ oxide-based composites and some information on Fe environment obtained by EXAFS simulation. Similar data on radial structure around Ce in Ce-component phases are not presented in this work as the Fe-based compounds played a leading role in adsorptive removal [3, 4]. Although it was impossible to explain the differences in adsorptive performances of ten inorganic composites to four aqueous anions based on the material structure studied by the standard characterisation methods, EXAFS spectroscopy was highly useful.

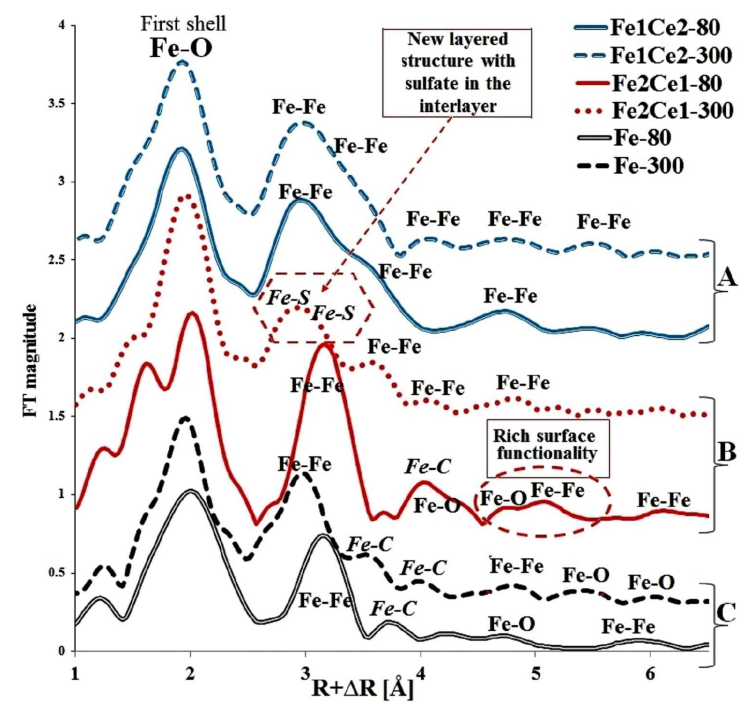

Fig. 4. Radial structure around Fe resulting from the Fourier transforms of Fe $K$-edge EXAFS oscillations for six samples of $\mathrm{Fe}-\mathrm{Ce}$ oxide-based composites and some data from EXAFS simulation. Effect of $300{ }^{\circ} \mathrm{C}$ treatment on phase transformations and surface functionality: $\mathrm{A}$ - absence of $\mathrm{Fe}-\mathrm{O}$ distances in $\mathrm{Fe}$ outer shells correlates with the low adsorptive removal of both Fe1Ce2-80 and Fe1Ce2-300, B - disappearance of $\mathrm{Fe}-\mathrm{O}$ distances in Fe outer shells in Fe2Ce1-300 (compared to Fe2Ce1-80) correlates with decrease in adsorption, $\mathrm{C}-$ more $\mathrm{Fe}-\mathrm{O}$ distances in Fe outer shells in Fe-300 (compared to Fe-80) correlates with increase in adsorption. Modified from [3, 4].

Considerate fitting of the local structure around $\mathrm{Fe}$ (its first, second and outer shells) not only provided a valuable information on the composite structures and their phase compositions, but also helped explaining adsorptive performances of these materials. EXAFS simulation of $\mathrm{Fe}$ local environment allowed association of the atomic scale structural data (with a particular focus on Fe outer shells) with the material surface reactivity. As anion exchangers these materials remove aqueous anions primarily via exchange of their surface $\mathrm{OH}^{-}$whose abundance on the $\mathrm{Fe} / \mathrm{Ce}$-based material surface was reflected by backscattering oscillations from both oxygen (O) and iron (Fe). Fe outer shells of the best adsorbents were simulated with both $\mathrm{Fe}-\mathrm{O}$ and $\mathrm{Fe}-\mathrm{Fe}$ paths chosen from Feff.inp files obtained using crystallography 
data of the relevant references. Extended local structure around $\mathrm{Fe}$ in the best $80^{\circ} \mathrm{C}$-sample (Fe2Ce1-80) was rich in backscattering oscillations from both $\mathrm{Fe}$ and $\mathrm{O}$ to $\mathrm{Fe}-$ absorber in its outer shells, Fig. 4. However, disappearance of these extended structures after thermal treatment at $300^{\circ} \mathrm{C}(\mathrm{Fe} 2 \mathrm{Ce} 1-300)$ correlated with a decrease in adsorptive removal of $\mathrm{F}^{-}$and $\mathrm{H}_{2} \mathrm{AsO}_{4}^{-}$(Fig. 3B) which most probably indicated a loss of active adsorptive sites, $\mathrm{OH}^{-}$. Similar regularities were observed for the other samples; see Fig. 4 and [3, 4].

In addition, treatment of EXAFS spectra provided much valuable information one of which helped explaining the unknown layered structures with the interlayer sulphate formed upon thermal treatment at $300^{\circ} \mathrm{C}$, which were also measured by XRD $[3,4]$. We think that this approach might be useful in characterisation of surface reactivity of other adsorbents and catalysts.

\section{Conclusions}

Complex metal oxides can be excellent anion exchangers for purification of water solutions and air. However, in order to advance, extend and make more efficient application of these materials in adsorption-based sciences and technologies, their characterisation shall be done on the level of speciation by going beyond the nanoscale; this applies to the knowledge of materials chemistry at synthesis and characterisation of the solids. To support the statements above, two groups of complex metal oxides were involved: three $\mathrm{Mg}-\mathrm{Al}-\mathrm{CO}_{3}$ layered double hydroxides and ten inorganic composites based on $\mathrm{Fe}-\mathrm{Ce}$ hydrous oxides.

It was not possible to explain a huge difference in adsorptive performances of three $\mathrm{Mg}-\mathrm{Al}-\mathrm{CO}_{3} \mathrm{LDHs}$ by their surface chemical and porous properties studied by standard characterisation methods. However, speciation level knowledge on the chemical elements ( $\mathrm{Al}, \mathrm{Mg}$ ), interlayer carbonate and hydration regularities allowed explaining the adsorption data. In addition to the above, all together research efforts were highly useful to deepen the knowledge on layered double hydroxides in general as well as on the anion removal mechanism.

An attempt to study the anion removal performances of ten composites based on $\mathrm{Fe}-\mathrm{Ce}$ hydrous oxides (as a function of Fe-to-Ce dosage ratios and treatment temperatures) could have been unsuccessful if the materials were not deeply characterised by EXAFS/XANES spectroscopy. At first, there was no correlation between adsorptive removals of four aqueous anions by the materials and their porosities. However, EXAFS simulations allowed establishing regularities between local structures around Fe (with a special emphasis on outer shells) and the adsorptive performances. The best removal was demonstrated by composite Fe2C1-80 whose simulated outer Fe shells resulted from oscillations from both $\mathrm{O}$ and $\mathrm{Fe}$ atoms and this might reflect the anion exchange sites, $\mathrm{OH}^{-}$, associated with Fe-oxide-based compounds. It is suggested that this approach might be projected on characterisation of surface reactivity of other adsorbents and catalysts.

We think that many researchers in other fields may have noted various inconsistencies between the material performances and their structural information obtained by standard characterisation tools. In this regard, we might be approaching the stage in science and technology when atomic scale characterisation of materials is to become inevitable.

\section{Acknowledgments}

An extensive research data used for this paper preparation were funded by King Abdullah University of Science and Technology (KAUST) (award $\mathrm{N}^{\circ} \mathrm{KUK}-\mathrm{C} 1-017-$ 12) and Netherlands Organization for Scientific Research (NWO) for EXAFS/XANES studies at Dutch-Belgian Beamline (DUBBLE) at the European SynchrotronRadiation Facilities (ESRF).

\section{References}

[1] A. Prüss-Ustünm, J. Wolf, C. Corvalán, R. Bos, M. Neira, Preventing Disease through Healthy Environments.

[2] F.G. Helfferich, Ion Exchange, McGraw Hill, New York 1962.

[3] N. Chubar, V. Gerda, D. Banerjee, G. Yablokova, J. Coll. Interf. Sci. 487, 388 (2017).

[4] N. Chubar, V. Gerda, D. Banerjee, J. Coll. Interf. Sci. 491, 111 (2017).

[5] N. Chubar, V. Gerda, O. Megantari, M. Mičušík, M. Omastova, K. Heister, P. Man, J. Fraissard, Chem. Eng. J. 234, 284 (2013).

[6] N. Chubar, J. Coll. Interf. Sci. 357, 198 (2011).

[7] S. Nikitenko, A. Beale, A. van der Eerden, S. Jacques, U. Leynaud, M. O'brien, D. Detollenaere, F. Kaptein, R.B. Weckhuysen, W. Bras, J. Synchr. Radiat. 15, 632 (2008).

[8] B. Ravel, M. Newville, J. Synchr. Radiat. 12, 537 (2005).

[9] L. Ingram, H. Taylor, Mineral. Magn. 36, 465 (1967).

[10] V. Rives, Layered Double Hydroxides: Present and Future, Nova Science Pub., 2011.

[11] N. Chubar, R. Gilmour, V. Gerda, M. Mičušík, M. Omastova, K. Heister, P. Man, J. Fraissard, V. Zaitsev, Adv. Coll. Interf. Sci. 245, 62 (2017). 